\title{
Incidental retained intrauterine Lippe's loop in 65 years old woman: a rare case report
}

\author{
Disha Bansal*, Ranjana Gupta, Aakriti Garg, Sakshi Srivastav, Nitu Chaudhary
}

Department of Obstetrics and Gynaecology, Rohilkhand Medical College and Hospital, Bareilly, India

Received: 18 November 2021

Revised: 10 December 2021

Accepted: 13 December 2021

\section{*Correspondence:}

Dr. Disha Bansal,

E-mail: dishabansal2702@gmail.com

Copyright: (c) the author(s), publisher and licensee Medip Academy. This is an open-access article distributed under the terms of the Creative Commons Attribution Non-Commercial License, which permits unrestricted non-commercial use, distribution, and reproduction in any medium, provided the original work is properly cited.

\begin{abstract}
Intrauterine contraceptive devices are a widely used method of contraception. It is cheap, easy and an effective method. The first intrauterine device was Lippe's loop which was double S shaped trapezoid loop introduced in 1962. Nowadays, third generation intrauterine devices are used which are effective for 5 and as well as 10 years. Here we presented a rare case of first generation of intrauterine device, that was, Lippe's loop in a 65 year old lady which was found as an incidental finding. Intrauterine device insertion without the knowledge of women can lead to the forgotten device which can adversely affect the health of women.
\end{abstract}

Keywords: Lippe’s loop, Missed IUCD, Forgotten IUCD

\section{INTRODUCTION}

Intrauterine contraceptive devices are effective, safe, long lasting and is a reversible method of contraception. ${ }^{1}$ Lippe`s loop was developed by Jack Lippe in 1960s and was manufactured by Ortho pharmaceutical corporation but it's production was stopped citing economic reasons. It was a plastic double $S$ loop trapezoid device that would closely fit the contours of uterine cavity and further reducing the chances of expulsion of the device. Due to the implant nature of the earlier intrauterine contraceptive devices, they were retained for long term use until the time of menopause. They are often found retained for years and many patients present into menopause still bearing a Lippes Loop forgotten. ${ }^{2}$

\section{CASE REPORT}

A 65 years old widow lady para 6, post-menopausal for 20 years, presented to gynaecology outpatient department of Rohilkhand medical college and hospital, Bareilly with complaints of vaginal discharge which was occasionally blood mixed, non-foul smelling, non-pruritic, associated with mild dull aching pain in lower abdomen for past 2 years. Patient didn't have any complaints prior to menopause. During her current visit, she had dirty discharge $\mathrm{p} / \mathrm{v}$.

When asked about contraceptive history, she reported to have undergone laparoscopic bilateral tubal ligation 25 years back. There was no history of intrauterine device insertion prior to tubal ligation to the best of her knowledge. There was no surgical or chronic medical problem.

On examination, her general condition was average. Laparoscopy scar was visible on per abdomen examination. Cervix was seen flushed with vagina, there was no growth. A blue coloured nylon thread was visible coming out of os with tip of thread buried into cervical tissue. This raised suspicion of our consultant for possibility of intrauterine device. There was also slight blood mixed discharge present at the time of examination. 
There was confusion in diagnosis as the patient didn't recall any IUD insertion in her reproductive life span, also she had undergone bilateral tubal ligation 25 years back.

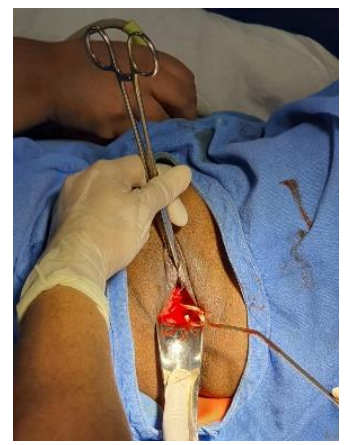

Figure 1: Removal of Lippe's loop.

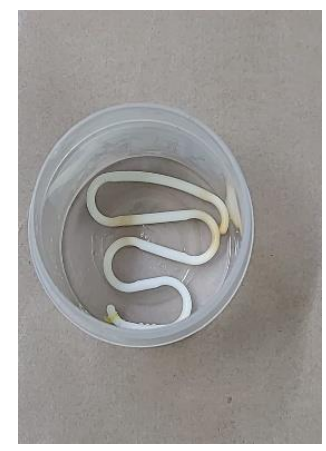

Figure 2: Lippe`s loop after removal.

A pap smear was taken which was negative for intraepithelial lesions or malignancy with atrophic features. An ultrasound was done for possibility of IUD. After careful observation and reconfirmation by X-ray, ultrasonologist diagnosed an intra uterine Lippe's loop. After confirmation, IUD removal was tried on OPD basis by traction of thread with artery forceps and hook but there was resistance to remove the device and the thread broke.

She was advised admission with the impression of retained IUD and given injectable antibiotic. The next day endometrial pipelle biopsy with Lippe's loop removal and ECC done with pyometra drainage under intravenous sedation. No malignancy was detected on endometrial curetting. On histopathological examination of endometrial tissue and endocervical curettage, few fragmented tissues were seen showing endometrial glands and stroma. No dysplasia/malignancy was seen.

The patient was discharged in satisfactory condition on second post op day. On follow up, she reported to have resolved her symptoms.

\section{DISCUSSION}

Removal of any misplaced or forgotten intrauterine device needs to be done. A forgotten IUCD can cause problems like infertility to postmenopausal bleeding, pain abdomen, fever and malaise. Complications can occur like ectopic pregnancy, bowel obstruction following perforation, uterine perforation, infections and rarely death. There was no established evidence that intrauterine device retained after menopause can cause cancer or other significant problems but such retention of intrauterine device did confuse the diagnosis of post-menopausal bleeding. ${ }^{3}$

The faculty of sexual and reproductive health care (FSRH) guidance on contraception for women aged over 40 years stated that pyometra and actinomycosis have been reported in postmenopausal women with retained IUCD and caused serious morbidity. Hence, IUCD needed to be removed rather than left in situ. ${ }^{4}$ According to WHO recommendations, removal of a misplaced IUCD must be done immediately after diagnosis was made.

\section{CONCLUSION}

Any retained intrauterine device should be removed on finishing of its lifespan or if is causing discomfort to patient or as soon as it is found that it has been forgotten. Patients should be counselled for follow up to prevent any forgotten cases of intrauterine device.

Funding: No funding sources

Conflict of interest: None declared

Ethical approval: Not required

\section{REFERENCES}

1. Kaneshiro B, Aeby T. Long-term safety, efficacy, and patient acceptability of the intrauterine copper $\mathrm{T}$ 380 A contraceptive device. Int J Women Health. 2010;2:211-20.

2. Ortho stops marketing Lippes loop; cites economic factors. Contracept Technol Update. 1985;6(11):14952.

3. Nagel TC. Intrauterine contraceptive devices: Complications associated with their use. Postgrad Med. 1983;73(3):155-64.

4. Faculty of sexual and reproductive health care. clinical effectiveness unit. Enquiry Ref. 2012:3941.

Cite this article as: Bansal D, Gupta R, Garg A, Srivastav S, Chaudhary N. Incidental retained intrauterine Lippe's loop in 65 years old woman: a rare case report. Int J Reprod Contracept Obstet Gynecol 2022;11:279-80. 